\title{
Experimental test of the $\rho(1-\alpha)$ evolution for rotational discontinuities: cluster magnetopause observations
}

\author{
A. Blagau ${ }^{1}$, G. Paschmann ${ }^{2}$, B. Klecker ${ }^{2}$, and O. Marghitu ${ }^{1}$ \\ ${ }^{1}$ Institute for Space Sciences, Bucharest, Romania \\ ${ }^{2}$ Max-Planck-Institut für extraterrestrische Physik, Garching, Germany \\ Correspondence to: A. Blagau (blagau@spacescience.ro)
}

Received: 5 September 2014 - Revised: 14 November 2014 - Accepted: 21 November 2014 - Published: 15 January 2015

\begin{abstract}
Rotational discontinuities (RDs) are governed by two relations: the Walén relation predicting that the plasma velocity observed in the deHoffmann-Teller frame equals the local Alfvén velocity and another relation that connects the variation in plasma mass density, $\rho$, to variations in the pressure anisotropy factor, $\alpha$, defined as $\alpha \equiv\left(p_{\|}-p_{\perp}\right) \mu_{0} / B^{2}$, so that $\rho(1-\alpha)$ is constant. While the Walén relation has become a standard tool for classifying magnetopause crossings as RDs, the $\rho(1-\alpha)=$ const. condition has never been directly verified at the same time, largely due to problems with determining $\rho$ when no ion composition measurements were available. In fact, to overcome the lack of composition information, the validity of the relation has often been assumed and the Walén relation reformulated so that variations in $\rho$ are replaced by variations in $\alpha$. In this paper we exploit the availability of high-time-resolution composition measurements on the Cluster spacecraft to directly test the $\rho(1-\alpha)=$ const. condition for three magnetopause crossings, identified as RDs from the application of the Walén relation to measurements of plasma ions and magnetic field by the CIS (Cluster Ion Spectrometry) and FGM (flux-gate magnetometer) instruments, respectively. We find that the relation is not fulfilled in either case. In one event, with a fairly large content of oxygen ions, the Walén test improved when the contribution from these ions was taken into account. Through comparisons of the measured ion densities with simultaneously measured total electron densities by the Waves of HIgh frequency and Sounder for Probing of Electron density by Relaxation (WHISPER) instrument, we were able to exclude the possibility that ion populations hidden to the CIS instrument because of their very low energies could have changed $\rho$ to match the $\rho(1-\alpha)=$ const. condition. We also excluded the possibility that energetic ions above the
\end{abstract}

CIS energy range could have sufficiently changed the true $\alpha$. It thus appears that the $\rho(1-\alpha)=$ const. condition, for reasons not presently understood, is not valid for the kind of RD-like structures we observe.

Keywords. Magnetospheric physics (magnetopause cusp and boundary layers)

\section{Introduction}

The clearest evidence for the occurrence of magnetic reconnection at Earth's magnetopause is the detection of accelerated plasma flows that meet the Walén relation. As plasma flows across a current layer with a nonvanishing normal magnetic field component, $B_{n}$, the plasma velocity, $\boldsymbol{V}$, tangential to that layer changes in response to the $\boldsymbol{j} \times \boldsymbol{B}_{n}$ force. For an ideal planar stationary rotational discontinuity (RD), the change in the plasma bulk velocity equals the change in Alfvén velocity (Hudson, 1970), i.e.,

$$
\begin{aligned}
\Delta \boldsymbol{V} & \equiv\left(\boldsymbol{V}_{\mathbf{2}}-\boldsymbol{V}_{\mathbf{1}}\right)= \pm \Delta \boldsymbol{V}_{\mathrm{A}} \\
& \equiv \pm\left(\sqrt{\left(1-\alpha_{2}\right)} \frac{\boldsymbol{B}_{2}}{\sqrt{\mu_{0} \rho_{2}}}-\sqrt{\left(1-\alpha_{1}\right)} \frac{\boldsymbol{B}_{1}}{\sqrt{\mu_{0} \rho_{1}}}\right),
\end{aligned}
$$

where the symbol $\Delta$ refers to changes relative to the upstream state (index 1) and $\boldsymbol{V}_{\mathrm{A}}$ is the local Alfvén velocity, corrected for the effect of pressure anisotropy, with $\alpha \equiv$ $\left(p_{\|}-p_{\perp}\right) \mu_{0} / B^{2}$. The positive (negative) sign in Eq. (1) applies if the normal components of the magnetic field and plasma velocity, $B_{n}$ and $V_{n}$, have the same (opposite) signs.

While Eq. (1) is usually applied to velocity measurements in the spacecraft frame, it is often more convenient to express the Walén relation in the deHoffmann-Teller (HT) frame. In 
the HT frame the flow velocity, $\boldsymbol{v}^{\prime} \equiv\left(\boldsymbol{V}-\boldsymbol{V}_{\mathrm{HT}}\right)$, is aligned with the magnetic field everywhere, and the Walén relation becomes (Sonnerup et al., 1987)

$\boldsymbol{v}^{\prime}= \pm \boldsymbol{V}_{\mathrm{A}} \equiv \pm \sqrt{(1-\alpha)} \frac{\boldsymbol{B}}{\sqrt{\mu_{0} \rho}}$.

Another key relation for an $\mathrm{RD}$ is obtained by considering the Alfvénic nature of the velocity component normal to the current layer. Together with mass conservation, this implies (e.g., Hudson, 1970) that

$\rho_{2}\left(1-\alpha_{2}\right)=\rho_{1}\left(1-\alpha_{1}\right)$.

This relation means that, in the presence of changing pressure anisotropies across an RD, it is not the mass density itself that remains constant but the mass density times a factor describing the pressure anisotropy.

In addition, normal momentum conservation requires that the total perpendicular pressures are balanced:

$p_{\perp 2}+B_{2}^{2} / 2 \mu_{0}=p_{\perp 1}+B_{1}^{2} / 2 \mu_{0}$.

Numerous detailed comparisons of plasma and magnetic field data taken across the magnetopause current layer and adjacent boundary layer with the Walén relation have been carried out, yielding strong evidence that the magnetopause often is an RD. For a recent review, see Paschmann et al. (2013).

In several of these studies, a modified form of the Walén relation was used, in which the mass density, $\rho$, in the expression for $\boldsymbol{V}_{\mathrm{A}}$ within as well as earthward of the magnetopause current layer was replaced by use of Eq. (3) and reference values in the magnetosheath (subscript 1), yielding the following two modified equations that were used, respectively, in the studies by Paschmann et al. (1986) and Phan et al. (1996) on the one hand and Sonnerup et al. (1987) and Phan et al. (2004) on the other:

$$
\begin{aligned}
\left(\boldsymbol{V}_{2}-\boldsymbol{V}_{1}\right) & = \pm \sqrt{\frac{\left(1-\alpha_{1}\right)}{\mu_{0} \rho_{1}}}\left(\boldsymbol{B}_{2} \frac{\left(1-\alpha_{2}\right)}{\left(1-\alpha_{1}\right)}-\boldsymbol{B}_{1}\right) \\
\boldsymbol{v}^{\prime} & = \pm(1-\alpha) \frac{\boldsymbol{B}}{\sqrt{\mu_{0} \rho_{1}\left(1-\alpha_{1}\right)}} .
\end{aligned}
$$

The rationale behind this procedure was that the plasma data had been taken by instruments that did not resolve ion mass and the moment computations assumed all ions were protons. This would lead to substantial errors in the computed mass densities if significant amounts of heavier ions were actually present in the measurements. For example, $5 \%$ $\mathrm{O}^{+}$ions by number would make the true mass density 1.8 times its apparent value. Failure to resolve them would thus significantly increase the Alfvén velocity. On the other hand, simulations have shown that these ions had much less effect on the pressures and thus on $\alpha$ (Paschmann et al., 1986).
Thus, replacing the density in the magnetopause and boundary layer by local $\alpha$ and the values $\rho_{1}$ and $\alpha_{1}$ at the magnetosheath reference time, where those ions are not expected, would at least partially correct the mass density for the presence of heavier ions. In fact, it was found that the $\rho$ values computed by assuming Eq. (3) were up to a factor of 2 higher than the $\rho$ actually measured. The resulting reduction in $\boldsymbol{V}_{\mathrm{A}}$ significantly improved the match between the measured velocities and those predicted by the Walén relation, thus supporting the reasoning behind this procedure.

Given the nature of the underlying measurements, no direct confirmation of the inferred ion composition was available, however, and thus the validity of the underlying Eq. (3) could not be verified. The only attempt to check Eq. (3) was provided by Fuselier et al. (1993), based on measurements provided by the AMPTE-CCE spacecraft during 27 low-latitude dayside magnetopause crossings. Because of the poor time resolution $(\sim 2 \mathrm{~min})$ of the composition measurements, the time history of $\rho(1-\alpha)$ could not be determined. Instead, ratios of $\rho(1-\alpha)$ between magnetosheath and boundary layer were obtained, after the regions were identified from high-resolution electron measurements. The authors found that that ratio was rarely equal to 1 . However, the paper states that only several of the crossings had reconnection signatures (high-speed flows), and it is only for those cases that a test of $\rho(1-\alpha)=$ const. is meaningful, while for the rest (the majority) it is not. Furthermore, the reconnection signatures are not actually shown in the paper, making it impossible to judge their quality.

The availability of high-time-resolution ion composition measurements with the CIS-CODIF (Cluster Ion Spectrometry-COmposition and DIstribution Function) instrument on Cluster has made it possible for the first time to follow the time series of $\rho(1-\alpha)$ across the magnetopause. In the following we will present observations for three magnetopause crossings that, based on tests of the Walén relations, are categorized as rotational discontinuities.

\section{Instrumentation}

In the present paper we use data from three instruments on board Cluster.

The magnetic field data are provided by the flux-gate magnetometer (FGM) experiment. This supplies the lowfrequency component of the magnetic field vector with an accuracy of about $0.1 \mathrm{nT}$ and a typical time resolution of 22 samples per second (see Balogh et al., 2001). In our analysis, we use the magnetic field measurements averaged over the CIS acquisition time of one spacecraft spin period, approximately $4 \mathrm{~s}$.

The plasma data are furnished by the CIS experiment (see Rème et al., 2001). CIS consists of two instruments, the Hot Ion Analyser (HIA) and the CODIF analyzer, which both measure the 3-D velocity distribution function of the ions. 
Combining energy per charge with time-of-flight measurements, CODIF is able to discriminate between various ion species present in the magnetosphere. HIA does not provide mass resolution but offers higher counting efficiency and better angular and energy resolution, as well as a higher saturation threshold, more suitable for dense magnetosheath plasmas.

Both instruments employ intensive onboard data processing in order to obtain plasma moments (number density, bulk velocity, pressure tensor, and heat flux) from the acquired velocity distribution functions. The plasma moments computed onboard are sent to the ground every spin period, i.e., about every $4 \mathrm{~s}$, being thus very useful for studying rapid events, such as fast boundary crossings. Reduced velocity distribution functions are transmitted as well, usually at lower time resolution, allowing the computation on the ground of plasma moments that can benefit from a more precise data calibration.

In addition to moments and reduced velocity distribution functions, a selected number of raw data are transmitted from CODIF, providing the full information on time-of-flight (TOF), energy per charge $(E / q)$, and incidence direction of the ions. Energy per charge and TOF measurements can be combined to infer the mass per charge $(M / q)$ of the ions:

$M / q=2\left(E / q+e \cdot U_{\mathrm{ACC}}\right) /(d / \mathrm{TOF})^{2} \cdot \delta$,

where $e \cdot U_{\mathrm{ACC}}$ is the energy gained by post-acceleration of the ions and $d$ is the length of the ion path. The quantity $\delta$ represents the energy loss in the thin carbon foil at the entry of the TOF section (see Rème et al., 2001). The raw data are essential for checking the onboard $M / q$ classification into four $M / q$ ranges for $\mathrm{H}^{+}, \mathrm{He}^{2+}, \mathrm{He}^{+}$, and $\mathrm{O}^{+}$.

The electron density data from the Waves of HIgh frequency and Sounder for Probing of Electron density by Relaxation (WHISPER) experiment onboard Cluster (Décréau et al., 2001) are compared with the ion density provided by CIS. Since WHISPER operates on a different principle than CIS, i.e., by analyzing, both actively and passively, resonant waves in the ambient plasma, the comparison offers good indications of the quality of ion data.

\section{Data treatment}

For the events to be presented in the next sections, the presence of minor ions species has been investigated making use of the raw data from CODIF. Figure 1, based on data recorded by Cluster 3 (C3) satellite on 14 March 2002, presents the raw events as a function of TOF and $E / q$ during a time interval of $100 \mathrm{~min}$ around the magnetopause transition to be analyzed in Sect. 4.1, when the satellite spends about equal time inside the magnetosphere and in the magnetosheath. The over-plotted vertical parabolic white lines delineate regions in the TOF-energy plane assigned by CODIF to different $M / q$ ranges, i.e., ions with $M / q=1$

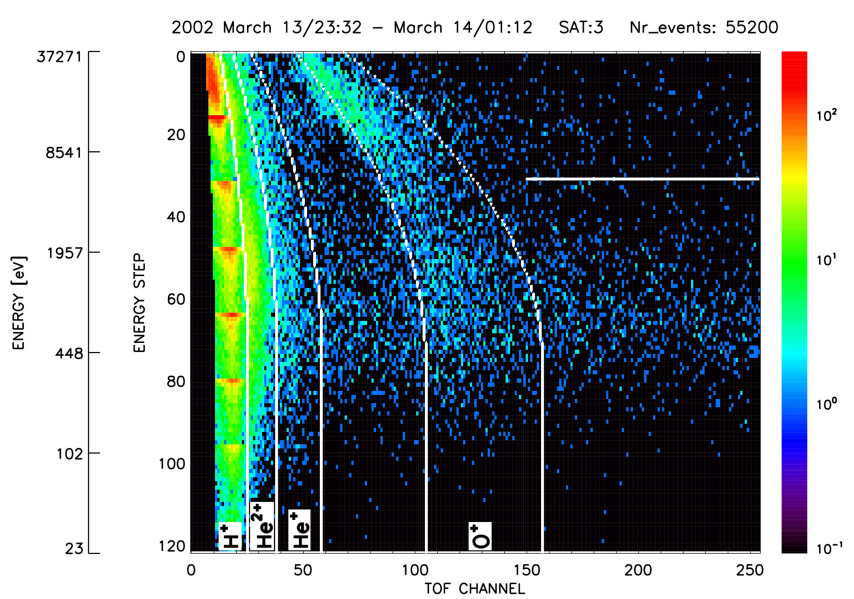

Figure 1. Raw events as a function of TOF and $E / q$ collected during a time interval of $100 \mathrm{~min}$ around the magnetopause transition on 14 March 2002, to be analyzed in Sect. 4.1. The parabolic white lines delineate regions assigned to different $M / q$ ranges, i.e., ions with $M / q=1\left(\mathrm{H}^{+}\right), M / q=2\left(\mathrm{He}^{2+}\right), M / q=4\left(\mathrm{He}^{+}\right)$, and $M / q=16\left(\mathrm{O}^{+}\right)$. The horizontal white line indicates the lower limit of the energy range used to compute the $\mathrm{O}^{+}$moments.

$\left(\mathrm{H}^{+}\right), M / q=2\left(\mathrm{He}^{2+}\right), M / q=4\left(\mathrm{He}^{+}\right)$, and $M / q=16$ $\left(\mathrm{O}^{+}\right)$. This kind of plot will be shown for each event. To simplify the comparison, data from the same satellite (i.e., C3), the same color range, and the same time interval $(\sim 100 \mathrm{~min}$ around the analyzed magnetopause transition, with roughly equal time inside and outside the magnetosphere) will be used.

In interpreting Fig. 1, one has to take into account that only 1 out of 10 events that fall into the proton region of the TOF-energy plane are transmitted, in order to improve the statistics of minor ions. Also, many of the events in the $\mathrm{He}^{2+}$ band are caused by large scatter of the TOF values of proton events (spillover effect). At medium energies, due to the high proton fluxes in the magnetosheath, this spillover effect can also contribute to all $M / q$ ranges (Mouikis et al., 2014). However, at high energies, Fig. 1 also shows that $\mathrm{O}^{+}$ is nicely separated from the other minor ions.

When studying the influence of minor ion species in the analysis, i.e., using the center-of-mass (COM) moments instead of proton moments, to check for the constancy of $\rho(1-$ $\alpha$ ) or the Walén relation, sometimes HIA and CODIF measurements have to be combined. For that purpose, the following procedure has been pursued (see for example Paschmann et al., 1986, Appendix 2, and Blagau, 2007, Appendix H): let $N_{\text {HIA }}, \boldsymbol{V}_{\text {HIA }}, \Pi_{\text {HIA }}$ designate the number density, bulk velocity, and momentum flux tensor provided by HIA, and let $N_{i}$, $V_{i}, \Pi_{i}$ be the moments corresponding to minor ion species $i$, computed from CODIF measurements. Firstly, the proton moments $N_{\mathrm{H}^{+}}, V_{\mathrm{H}^{+}}, \Pi_{\mathrm{H}^{+}}$have been computed by taking into account that HIA is not able to discriminate between the 
ion species. The following relations have been used:

$N_{\mathrm{H}^{+}}=N_{\mathrm{HIA}}-\gamma^{-1} N_{i}$

$\boldsymbol{V}_{\mathrm{H}^{+}}=\left(N_{\mathrm{HIA}} \boldsymbol{V}_{\mathrm{HIA}}-N_{i} \boldsymbol{V}_{i}\right) / N_{\mathrm{H}^{+}}$

$\Pi_{\mathrm{H}^{+}}=\Pi_{\mathrm{HIA}}-\gamma^{-1} \Pi_{i}$,

with $\gamma=\sqrt{m_{\mathrm{H}^{+}} / m_{i}}$. Then the COM quantities have been obtained using well-known equations (see, e.g., the references cited above). For example, the component $x y$ of the thermal pressure tensor $\mathbf{P}$ is

$\mathbf{P}_{\mathrm{COM}}^{x y}=\Pi_{H^{+}}^{x y}+\Pi_{i}^{x y}-\rho_{\mathrm{COM}} \boldsymbol{V}_{\mathrm{COM}}^{x} \boldsymbol{V}_{\mathrm{COM}}^{y}$,

with $\rho_{\mathrm{COM}}$ and $\boldsymbol{V}_{\mathrm{COM}}$ being the COM mass density and bulk velocity vector, respectively.

It is worth noting that, because of the large separation in mass per charge, it is much easier to analyze the effect of the $\mathrm{O}^{+}$population on $\mathrm{COM}$ moments, compared to $\mathrm{He}^{2+}$ or $\mathrm{He}^{+}$ions. In addition, the separation in energy between the $\mathrm{O}^{+}$ions and magnetosheath protons makes possible a relatively accurate estimation of $\mathrm{O}^{+}$moments. Note also that the oxygen ions are 4 times heavier than the $\mathrm{He}^{2+}$ or $\mathrm{He}^{+}$ions; therefore, for the same abundance, their contribution to the COM moments will be higher.

For the events to be presented in the next sections, the magnetopause normal direction has been estimated by applying a constrained form of the minimum variance analysis of the magnetic field (MVA), which imposes a vanishing normal magnetic field component, i.e., $B_{n}=0$ (see Sonnerup and Scheible, 1998). The standard, unconstrained MVA provided either a poor identification of normal direction (i.e., small eigenvalue ratio) and/or unreasonably high values for $B_{n}$. Thus no meaningful $B_{n}$ could be obtained. By contrast, the constrained MVA provided a good identification of the normals, albeit at the expense of forcing $B_{n}$ to 0 . The inconsistency arising from the application of constrained MVA to magnetopauses believed to be RDs is justified by the small values of $B_{n}$ implied by the small reconnection rate at the magnetopause. To double-check the results, the orientation of the constrained MVA normals have been compared either with the normals obtained from timing analysis (TA; see e.g., Haaland et al., 2004) or from the minimum Faraday residue analysis (MFR; Khrabrov and Sonnerup, 1998b) and found to be in good agreement. Also, a good agreement has been obtained by comparing the magnetopause normal velocity provided by TA or MFR and the projection of HT velocity along the constrained MVA normals.

The plasma pressures perpendicular and parallel to the magnetic field, $p_{\perp}$ and $p_{\|}$, respectively, were computed based on the local orientation of $\boldsymbol{B}$.

\section{Observations}

In this section, three magnetopause crossings are presented where the tests of the Walén relation indicate they are rotational discontinuities and the availability of composition measurements from the CODIF instrument allows for a detailed check of the $\rho(1-\alpha)=$ const. condition. The observations also allow investigating whether the improvement in the Walén test results assuming the validity of this condition is consistent with the composition actually measured (see next section).

\subsection{The magnetopause crossing on 14 March 2002}

\subsubsection{Overview}

The first event to be presented is a high-latitude dayside magnetopause crossing at around [7.9, -3.0, 8.0] $R_{\mathrm{E}}$ in GSM coordinates. The four satellites were in a tetrahedral configuration, the separation distance being around $100 \mathrm{~km}$.

Figure 2 presents time series of the key physical quantities, based on measurements taken onboard Cluster 3 . An inbound magnetopause traversal from the magnetosheath to the magnetosphere occurs at around 01:05:40 UT.

\subsubsection{HT and Walén analysis}

Figure 3 shows the results from HT and Walén tests for the time interval indicated by the dashed vertical lines in Fig. 2. The procedure for determining the HT frame consists of finding the transformation velocity, $\boldsymbol{V}_{\mathrm{HT}}$, that minimizes the residual electric field in the least-squares sense (Sonnerup et al., 1987; Khrabrov and Sonnerup, 1998a). To show the result, the left plot compares, component by component, the measured convection electric field $\boldsymbol{E}_{\mathrm{c}}=-\boldsymbol{V} \times \boldsymbol{B}$ with the convection electric field $\boldsymbol{E}_{\mathrm{HT}}=-\boldsymbol{V}_{\mathrm{HT}} \times \boldsymbol{B}$ based on the determined HT velocity. The slope of the fit line (i.e., 1.01), and the correlation coefficient $(0.99)$ testify to a good identification of the HT frame. The ratio between the mean square electric field calculated in the HT frame $(D)$ and in the initial frame $\left(D_{0}\right)$ shows that $99 \%$ of the initial electric field has been transformed away in the HT frame.

The right part of Fig. 3 shows the result of the Walen test, comparing the plasma velocity in the HT frame with the local Alfvén velocity (Eq. 2). The correlation coefficient of -0.99 is close to the ideal values of \pm 1 , whereas the value of the slope $(-0.68)$ is lower than the values predicted for an ideal $\mathrm{RD}$ (i.e., \pm 1 ), but this is quite common for the magnetopause (see, e.g., Paschmann et al., 2005).

The negative Walén slope means that the normal components of the magnetic field and plasma velocity must be antiparallel. With reconnection implying inflow into the magnetosphere, $B_{n}$ must therefore be directed outward in this case, $B_{n}>0$. For a high-latitude dayside crossing and a reconnection X-line located at low latitudes, one would expect $B_{n}<0$ and thus a positive Walén slope. So the $\mathrm{X}$-line must have been located at higher latitudes than the crossing latitude. This configuration explains why no plasma jetting is observed, i.e. the implied $\boldsymbol{j} \times \boldsymbol{B}$ force is directed against the tailward magnetosheath flow. Note that the magnetic shear 


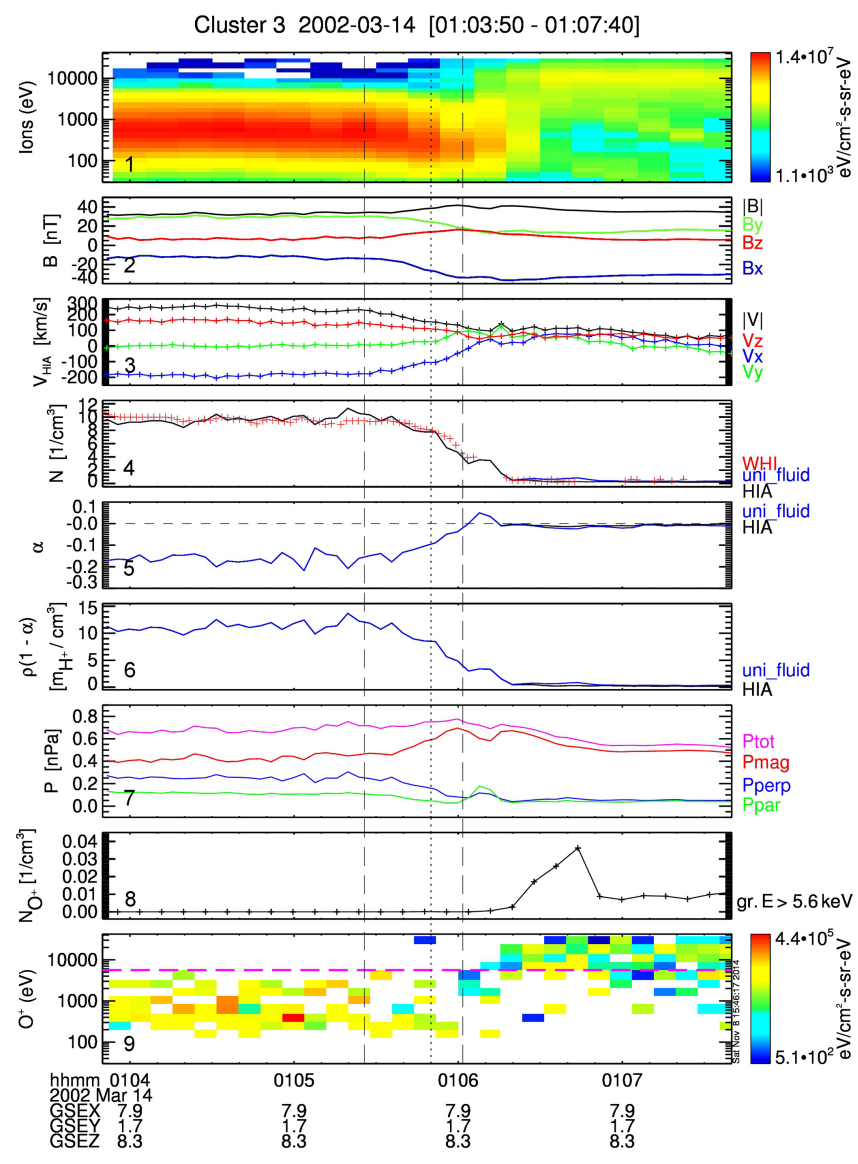

Figure 2. Magnetic field and plasma data for the inbound crossing from 14 March 2002 by Cluster 3. The top panel shows the HIA energy flux spectrogram; the next panels show the magnetic field magnitude and components, followed by the HIA bulk velocity magnitude and components; panel 4 shows the HIA density (in black), superimposed on the WHISPER total electron density (red symbols), followed by the pressure anisotropy factor $\alpha$ and $\rho(1-\alpha)$ in panels 5 and 6; panel 7 shows the magnetic field pressure (red), perpendicular (blue) and parallel (green) ion pressure, and the sum of the magnetic and perpendicular ion pressures (magenta). The last two panels give the $\mathrm{O}^{+}$density and energy spectrogram, as determined from the CODIF measurements. For the $\mathrm{O}^{+}$density, only the four highest energy channels, roughly above the $5.6 \mathrm{keV}$ threshold indicated by the horizontal magenta line in the last panel, have been taken into account. The magnetic field and plasma bulk velocity components are in GSE coordinates, with $x$ in blue, $y$ in green, and $z$ in red. In panels 4,5 , and 6 , the quantities which include the uni-fluid correction are shown in blue. The black vertical dashed lines indicate the interval used for the HT/Walén analysis, while the vertical dotted line roughly indicates the center of the current layer.

for this case is only $\approx 45^{\circ}$, making the reconnection configuration very different from the usual expectation for antiparallel fields. The low magnetic shear also contributes to the lack of jetting for this event.
CLUSTER 3

Date: 2002-03-14 Interval: [01:05:25- 01:06:01] nr. points: 27
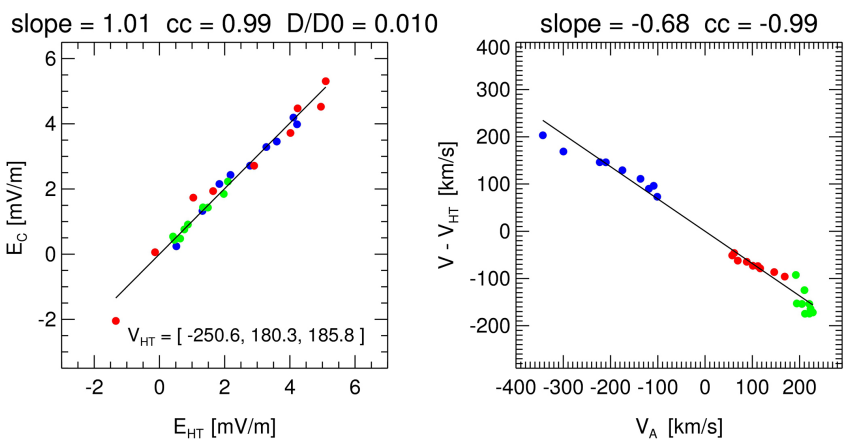

Figure 3. Left: plot of the GSE components of the convection electric field, $\boldsymbol{E}_{\mathrm{c}}=-\boldsymbol{V} \times \boldsymbol{B}$, versus the corresponding components of the deHoffmann-Teller electric field, $\boldsymbol{E}_{\mathrm{HT}}=-\boldsymbol{V}_{\mathrm{HT}} \times \boldsymbol{B}$. Right: scatterplot of the components of $\boldsymbol{v}^{\prime} \equiv\left(\boldsymbol{V}-\boldsymbol{V}_{\mathrm{HT}}\right)$ versus the components of $\boldsymbol{V}_{\mathrm{A}}$. In both plots the $x, y$, and $z$ components are shown in blue, green, and red, respectively.

\subsubsection{Magnetopause orientation and motion}

All four Cluster satellites recorded a very regular magnetic transition, similar to the evolution presented in the second panel of Fig. 2. This feature allowed for a precise determination of the magnetopause crossing times by fitting the magnetic field components along the maximum variance direction (see the procedure described in Haaland et al., 2004). The magnetopause orientation, thickness, and velocity along the normal direction has been subsequently estimated assuming a planar geometry and a constant velocity motion. The obtained magnetopause normal has been compared with the individual normals obtained from the constrained MVA and found to be in good agreement, the difference in orientation being below $3^{\circ}$. This supports the assumption of a local, i.e., on the length scale of the Cluster constellation, planar geometry for the magnetopause. The magnetopause thickness has been estimated to be around $1060 \mathrm{~km}$, to be compared with the average proton gyroradius of around $44 \mathrm{~km}$ and the average ion inertial length of around $82 \mathrm{~km}$ for this transition. The magnetohydrodynamic treatment of the discontinuity is therefore well justified.

From the known HT velocity, $\boldsymbol{V}_{\mathrm{HT}}$, and magnetopause normal, we can calculate the magnetopause velocity, and obtain $\approx 52 \mathrm{~km} \mathrm{~s}^{-1}$, to be compared with $\approx 41 \mathrm{~km} \mathrm{~s}^{-1}$ obtained from the timing analysis. The positive velocity values are consistent with an inbound crossing. On the other hand, the normal magnetic field obtained from the TA normal is $B_{n}=-1.4 \mathrm{nT}$, its negative sign being inconsistent with the negative sign of the Walén slope. However, to remove this inconsistency would require a shift of the magnetopause normal by only about $2.5^{\circ}$. 


\subsection{4 $\mathrm{O}^{+}$Ions}

In Fig. 1, the 2-D histogram based on the raw events recorded by CODIF on board C3 shows a faint oxygen population. Following the procedure described in Sect. 3, the COM quantities have been obtained based on the HIA onboard moments and on $\mathrm{O}^{+}$moments computed on the ground from the velocity distribution functions transmitted by CODIF. In case of oxygen, only the four highest energy channels of the velocity distribution function, roughly above $5.6 \mathrm{keV}$, were considered, consistent with Fig. 1. The last panel in Fig. 2 presents the oxygen differential energy flux spectrogram provided by CODIF. The $5.6 \mathrm{keV}$ threshold is depicted by the magenta horizontal line in Fig. 2, which corresponds to the white horizontal line in Fig. 1. The second panel from the bottom in Fig. 2 presents the evolution of the $\mathrm{O}^{+}$number density obtained under these conditions. The raw data collected in the magnetosheath just outside the analyzed transition (not shown) reveal a very faint population of "genuine" $\mathrm{O}^{+}$, supporting the conclusion of an open magnetosphere.

\subsubsection{Densities, pressures, and $\rho(1-\alpha)$}

In the fifth and sixth panels in Fig. 2, the time series of the plasma pressure anisotropy factor $\alpha$ and of $\rho(1-\alpha)$ are shown with black lines. One notices that, in spite of the RD identification of the magnetopause transition, the condition $\rho(1-\alpha)=$ const. is not fulfilled by far.

The blue lines in panels 4, 5, and 6 in Fig. 2 present the evolution of uni-fluid quantities in terms of number density, i.e., $N_{\mathrm{H}^{+}}+N_{\mathrm{O}^{+}}\left(m_{\mathrm{O}^{+}} / m_{\mathrm{H}^{+}}\right)$, plasma pressure anisotropy factor $\alpha_{\mathrm{COM}}$, and $\rho_{\mathrm{COM}}\left(1-\alpha_{\mathrm{COM}}\right)$. As one can observe, they basically lie on top of the black lines, corresponding to HIAbased quantities, proving thus that the $\mathrm{O}^{+}$ion population did not play a significant role in the analysis. Also, the results from HT and Walén tests did not change. These findings are not so surprising if one looks on the last two panels, which show that basically no oxygen ions are detected during the magnetopause traversal.

The seventh panel in Fig. 2 confirms that the total perpendicular pressure is conserved for this crossing, as required.

The low level of fluctuations and the gradual variation of the plasma parameters seen in Fig. 2 support the assumption of stationarity for this event and increase the accuracy of the moment data. CIS needs a full spacecraft spin $(4 \mathrm{~s})$ for data acquisition so that rapid variations cause time aliasing.

A final point concerns the good agreement between the HIA ion density and WHISPER total electron density in the fourth panel of Fig. 2. In Sect. 5 we will assess whether this agreement rules out the presence of a significant "hidden" ion population outside the instrument detection range.

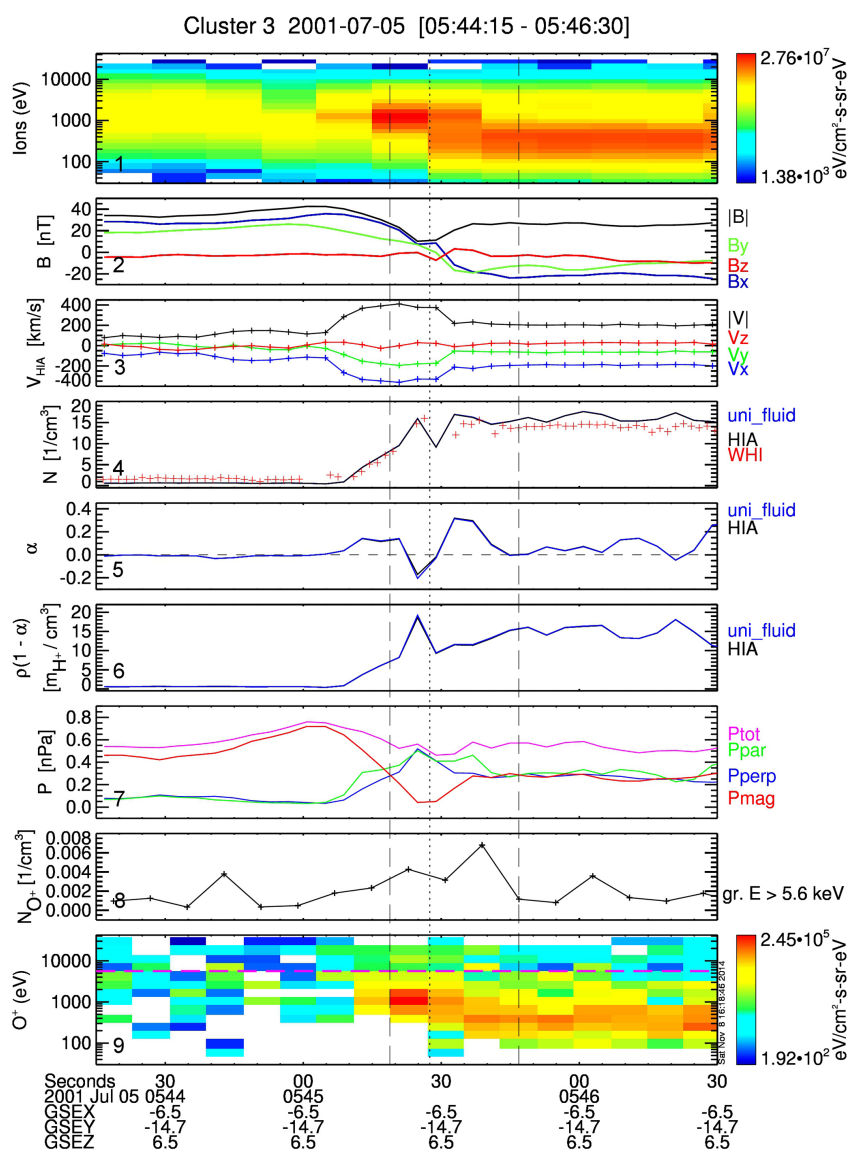

Figure 4. Plasma and magnetic field parameters for an outbound magnetopause crossing on 5 July 2001 as measured by Cluster 3 . The layout is the same as in Fig. 2.

\subsection{The magnetopause crossing on 5 July 2001}

\subsubsection{Overview}

This magnetopause transition is one of many crossings on 5 July 2001 analyzed in Paschmann et al. (2005). It is an outbound crossing that took place on the magnetopause flank, at around $[-6.5,-14.7,6.5] R_{\mathrm{E}}$ in GSE. The separation distance between the four Cluster satellites was around $2400 \mathrm{~km}$.

Figure 4 presents the evolution of the same parameters as in Fig. 2 from Sect. 4.1. The transition is characterized by a large magnetic shear of almost $180^{\circ}$ and pronounced plasma jetting (see the third panel from the top). Again, the good agreement between the HIA ion density and the WHISPER electron density (fourth panel) is evidence that HIA is measuring the full plasma distribution. As shown by the seventh panel, the total perpendicular pressure is reasonably well preserved, in spite of the deep minimum in $B$ shown in the second panel. This indicates that the HIA moments are not significantly affected by time aliasing resulting from their rapid variations during the Walén interval. The magne- 
CLUSTER 3

Date: 2001-07-05 Interval: [05:45:18 - 05:45:46] nr. points: 21
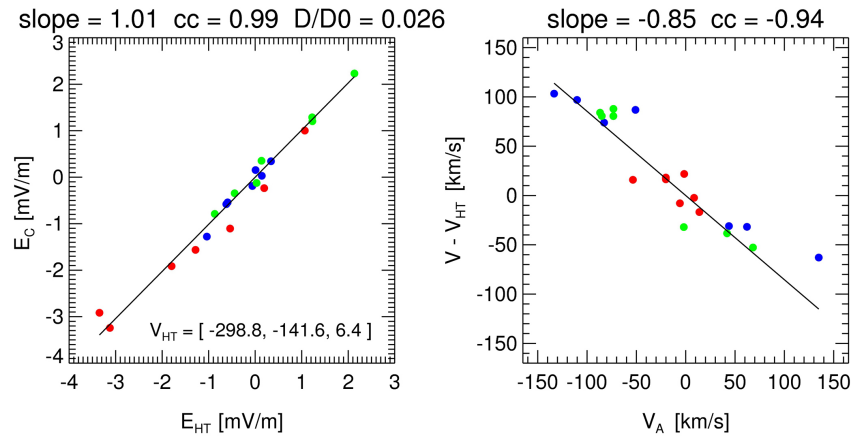

Figure 5. HT frame determination and Walén relation test for the 5 July 2001 crossing, with the same layout as Fig. 3.

topause thickness has been estimated to be around $552 \mathrm{~km}$, to be compared with the average proton gyroradius of around $100 \mathrm{~km}$ and the average ion inertial length of around $62 \mathrm{~km}$.

\subsubsection{HT and Walén analysis}

Figure 5 shows the results from the HT and Walén analysis for the time interval indicated by the dashed vertical lines in Fig. 4. The good HT frame identification and the Walén slope magnitude of 0.85 demonstrate that the magnetopause can be considered an RD. The negative sign of the slope implies that $B_{n}$ must have been positive, i.e., directed outward, indicating that $\mathrm{C} 3$ was crossing the magnetopause tailward of an $\mathrm{X}$-line, where the tailward flow of the plasma is enhanced due to the relaxation of magnetic tension in the newly reconnected field lines, consistent with the observed plasma jetting.

\subsubsection{Orientation and motion}

The constrained MVA and MFR normals lie within $5^{\circ}$ of each other. The MFR analysis provides a magnetopause normal velocity of $\approx-35 \mathrm{~km} \mathrm{~s}^{-1}$, very close to the normal component of $\boldsymbol{V}_{\mathrm{HT}}$, the negative sign being consistent with the observed outbound crossing. Note that the transitions at the other Cluster spacecraft look very different, making a timing analysis to obtain the magnetopause orientation impossible.

\subsection{4 $\mathrm{O}^{+}$ions and $\rho(1-\alpha)$}

Figure 6 is the counterpart of Fig. 1 from Sect. 4.1. One can see that practically no $\mathrm{O}^{+}$events have been detected for this transition. Therefore, it is not surprising that, in panels 4, 5, and 6 in Fig. 4, the blue lines representing the evolution of uni-fluid quantities in terms of number density, pressure anisotropy factor $\alpha$, and $\rho_{\mathrm{COM}}\left(1-\alpha_{\mathrm{COM}}\right)$ lie basically on top of the black lines that correspond to the HIA-based quantities.

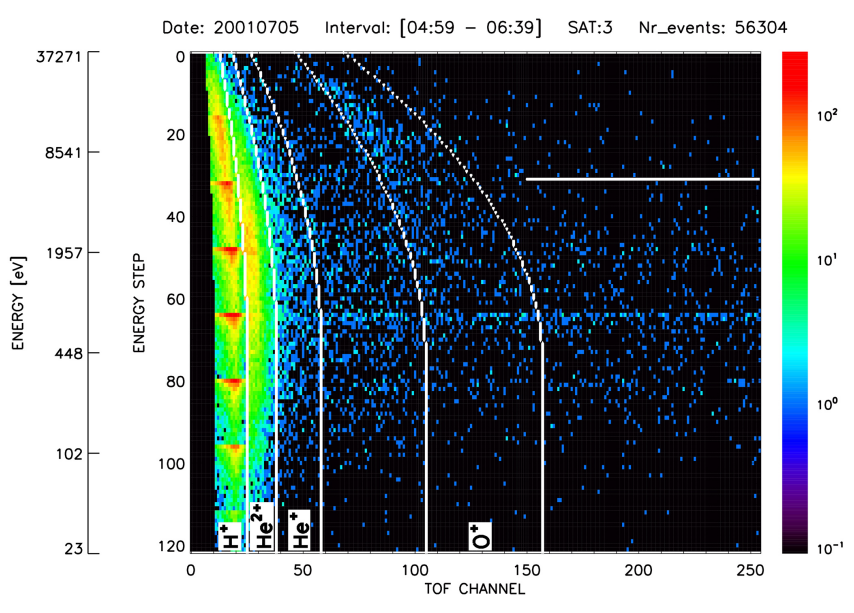

Figure 6. Raw events as a function of TOF and $E / q$ for the 5 July 2001 crossing.

The sixth panel of Fig. 4 shows that $\rho(1-\alpha)$ is not conserved across the transition, its evolution being practically dictated by the variations in plasma density.

\subsection{The magnetopause crossing on 26 January 2001}

\subsubsection{Overview}

On 26 January 2001, the Cluster spacecraft recorded multiple magnetopause transitions in the high-latitude northern magnetopause, around [5.0, 7.8, 9.2] $R_{\mathrm{E}}$ in GSE coordinates. This series of events has been studied by Phan et al. (2004), where the authors presented convincing evidence in favor of a continuous magnetic reconnection process, active over a period of more than $2 \mathrm{~h}$. During that time interval, $10 \mathrm{mag}$ netopause current layer crossings per satellite were detected, the Walén relation being satisfied with remarkable accuracy for all of them.

Most of the magnetopause transitions from 26 January 2001 occur between the magnetosheath and magnetopause boundary layer, involving relatively small changes in the plasma density and thus not being suitable for testing the balance between $\rho$ and $\alpha$. The magnetopause transition beginning at around 10:42 UT, presented in Fig. 7, is one exception since for that case the plasma number density in the magnetopause current layer drops from around $13 \mathrm{~cm}^{-3}$ to around $5.5 \mathrm{~cm}^{-3}$. Immediately afterward, the satellite enters the magnetopause boundary layer, where the density and bulk velocity are higher (see panels three and four). The situation suggests nonuniform conditions in the magnetosheath plasma, with a locally higher density at the site where the boundary layer plasma crossed the magnetopause and was accelerated.

During the time interval indicated with dashed vertical lines, used in the HT and Walén tests presented in Fig. 8, the satellite crosses the magnetopause current layer completely 


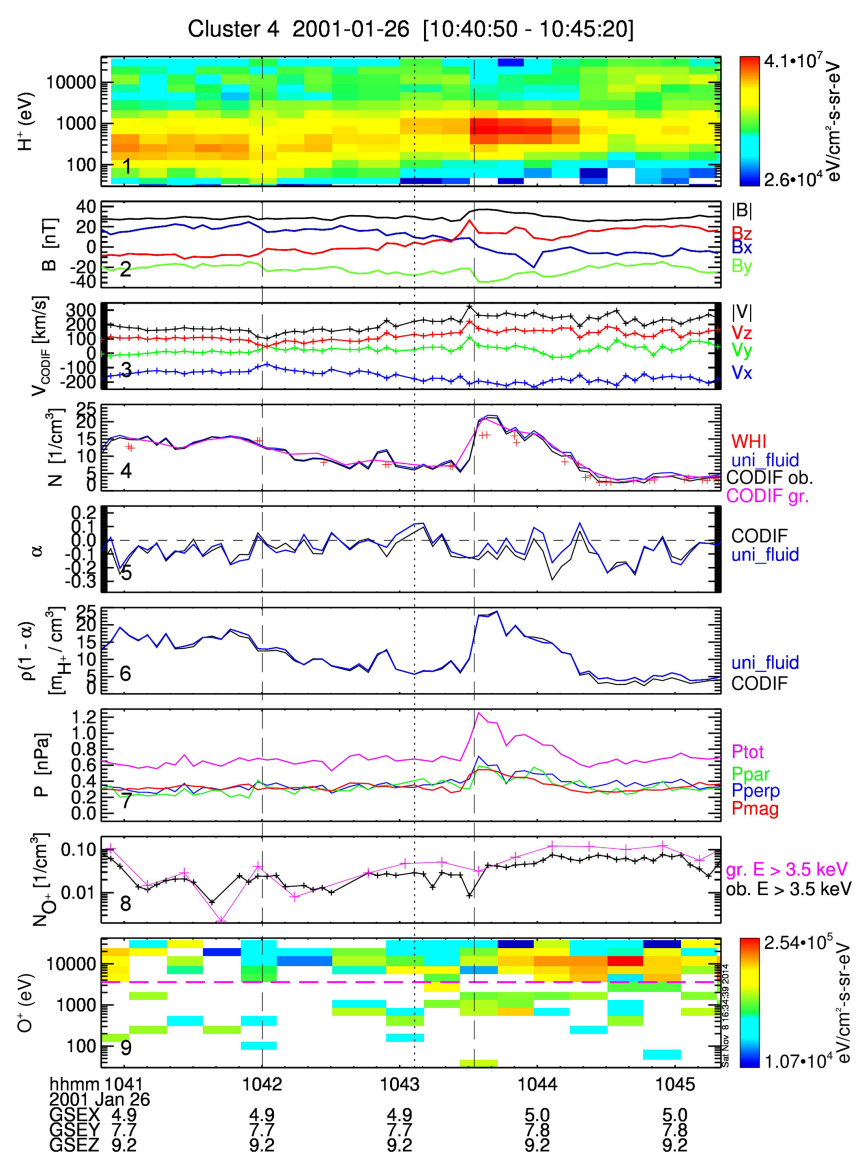

Figure 7. Plasma and magnetic field parameters for the inbound transition from 26 January 2001 as measured by Cluster 4 satellite. The layout is the same as in Fig. 2.

and reaches the magnetopause boundary layer as the magnetic field and plasma bulk velocity roughly change from the magnetosheath to the magnetospheric values. The analysis interval chosen provides the highest Walén slope for this transition, ending just where the total perpendicular pressure (panel seven) starts to increase.

Contrary to the previous two cases, we used CODIF rather than HIA data for the 26 January 2001 crossing, the reason being that the CODIF instrument on Cluster 4 (C4) operated in low-sensitivity mode, thus avoiding the common problem of detector saturation in the magnetosheath. In support of this, the fourth panel of Fig. 7 compares the WHISPER total electron density (red symbols) with the proton number density computed onboard (black line) and that computed on the ground (magenta line), the latter benefiting from the routine instrument calibration procedure. The good agreement between these three quantities means that one can use the onboard proton moments in the analysis, taking advantage of the higher time, energy, and angular resolution of the velocity distribution functions accumulated onboard. Note that by using CODIF data, one avoids potential intercalibration prob-

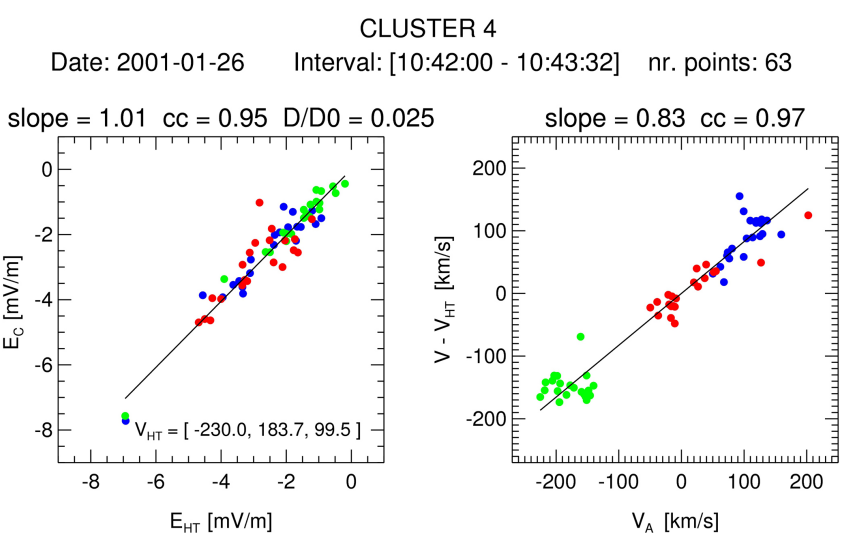

Figure 8. HT and Walén analysis for the 26 January 2001 crossing, with the same layout as Fig. 3.

lems between HIA and CODIF when computing the uni-fluid quantities.

\subsubsection{HT and Walén analysis}

Figure 8 presents the results of the HT and Walén analysis for the time interval indicated by vertical dashed lines in Fig. 7. Uni-fluid quantities, based on onboard proton and oxygen moments above $3.5 \mathrm{keV}$, have been used in the analysis. When using proton moments alone, the Walén slope decreases from 0.83 to 0.76 , providing evidence that the $\mathrm{O}^{+}$ ions do have some influence on the outcome of the test. This finding remains valid when the analysis is performed on intervals of different length or when the oxygen ground-based moments (interpolated at spin resolution) are used.

The positive Walén slope means that $B_{n}$ must have been negative, i.e., inward pointing, implying that the reconnection X-line was located at lower latitudes than the crossing.

\subsubsection{Orientation and motion}

By applying the constrained MVA and MFR analysis to data provided by all Cluster satellites, one obtains normals less than $3^{\circ}$ apart from each other. The separation distance between the four Cluster satellites was around $600 \mathrm{~km}$. In the case of $\mathrm{C} 4$, the magnetopause normal velocity provided by MFR is around $35 \mathrm{~km} \mathrm{~s}^{-1}$, in good agreement with the normal component of $\boldsymbol{V}_{\mathrm{HT}}$, which is around $30 \mathrm{~km} \mathrm{~s}^{-1}$. The transitions at the other Cluster spacecraft look very different, making a timing analysis to obtain the magnetopause orientation impossible.

The estimated magnetopause thickness for this transition was roughly $1600 \mathrm{~km}$, much greater than the proton gyro radius and the proton inertial length that both have an average value of around $80 \mathrm{~km}$. 


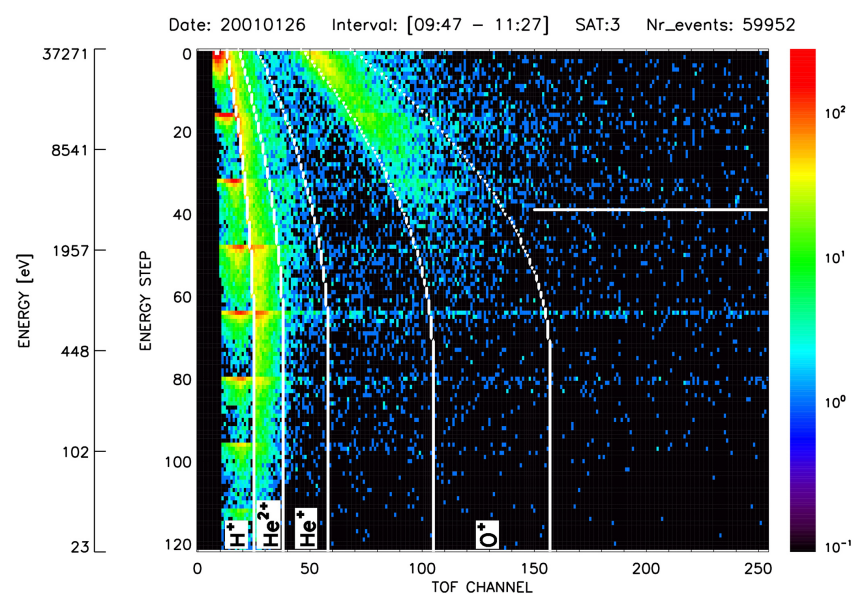

Figure 9. Raw events as a function of TOF and $E / q$ for the 26 January 2001 crossing.

\subsection{4 $\mathrm{O}^{+}$ions and $\rho(1-\alpha)$}

For the purpose of this paper, the magnetopause transitions from 26 January 2001 are particularly interesting due to the relatively high abundance of $\mathrm{O}^{+}$ions, up to $\sim 2.5 \%$ in number density, on the magnetospheric side. Figure 9 presents the raw CODIF data provided by $\mathrm{C} 3$. One notices a significant number of "genuine" $\mathrm{O}^{+}$events, i.e., not created by the protons' spillover, in the highest energy channels, i.e., above around $3.5 \mathrm{keV}$.

CODIF can also provide the moments computed onboard corresponding to the "genuine" $\mathrm{O}^{+}$population observed in Fig. 9 since, for each ion species, the instrument actually computes, and sends to the ground, the density, velocity vector, and pressure tensor corresponding to three abutting energy intervals. The highest such energy interval extends above $3.5 \mathrm{keV}$, covering the five highest energy channels of the velocity distribution function received on the ground. The second panel from the bottom in Fig. 7 presents the evolution of the onboard (black) and ground (magenta) number density of oxygen ions corresponding to this energy interval. The two quantities agree very well and will both be used in the following analysis. One observes a significant change in the $\mathrm{O}^{+}$number density across the magnetopause, from around $0.01 \mathrm{~cm}^{-3}$ in the magnetosheath to roughly $0.08 \mathrm{~cm}^{-3}$, in the magnetopause boundary layer and magnetosphere.

The sixth panel of Fig. 7 shows the evolution of $\rho(1-\alpha)$, computed based on proton (black) and on uni-fluid (blue) moments. For the time interval that was used to provide evidence for an RD, the quantity is far from constant, basically varying in the same way as the plasma density. One arrives at the same conclusion when uni-fluid instead of proton moments are used. Note that a small difference between the two lines can be observed in the inner part of the magnetopause boundary layer, after 10:44:30, when the proton density decreases and the oxygen density increases.
For the chosen interval of analysis, the total perpendicular pressure is well preserved, as can be seen in the seventh panel of Fig. 7. The magnetic and plasma pressures start to increase abruptly in the magnetopause boundary layer, a feature that has been observed for other inbound crossings on 26 January 2001 as well, suggesting it to be the cause of magnetopause radial motion.

\section{Summary and discussion}

\subsection{Basic observation}

The $\rho(1-\alpha)=$ const. condition should hold for an ideal RD, being based on the same assumptions as the Walén relation. In the analysis in Sect. 4, careful attempts have been made to verify the relation experimentally. After having concluded that the cases represent RDs, through tests of the Walén relation in the deHoffmann-Teller frame (Eq. 2), we have carefully examined the contribution of $\mathrm{O}^{+}$ions to the plasma center-of-mass moments but find that the $\rho(1-\alpha)$ differs widely from a constant. Instead it essentially varies in the same way as the density, something already pointed out by Fuselier et al. (1993).

For these tests we have used the most accurate ion data sets, i.e., the onboard HIA or CODIF low-sensitivity moments, which are practically unaffected by instrument saturation and are based on the higher time, energy, and angular resolution velocity distribution functions. As discussed below, a key element is good agreement of the ion densities with the WHISPER electron densities. Then, the analysis checked and took into account the possible influence from minor ion species (i.e., oxygen). In computing the $\mathrm{O}^{+}$moments, only the CODIF highest energy channels have been used, thus excluding the contribution from false $\mathrm{O}^{+}$events generated by the high magnetosheath proton fluxes through the spillover effect.

Due to the proton spillover in the adjacent M/q channels, it is impossible to obtain reliable $\mathrm{He}^{2+}$ moments from CODIF. For the first two cases analyzed in Sect. 4, the $\mathrm{He}^{2+}$ abundance measured by the ACE satellite in the solar wind was around $3-4 \%$, implying a mass density correction of up to $14 \%$ with respect to that inferred from HIA, assuming protons only. For the 26 January case, the $\mathrm{He}^{2+}$ abundance was around $10 \%$, with the corresponding mass density correction of up to $33 \%$. Note that since the $\mathrm{He}^{2+}$ density is lower on the magnetospheric side, the evolution of $\rho$ and $(1-\alpha)$ are even more unbalanced. The correction to $\alpha$ is expected to be small since the two populations have approximately the same bulk velocity (Paschmann et al., 1989). The situation is opposite to the case of $\mathrm{O}^{+}$ions that have higher densities on the magnetospheric side and a relative velocity with respect to the bulk of plasma, provided by the magnetosheath.

As a possible explanation for the result obtained by Fuselier et al. (1993) about the nonconstancy of $\rho(1-\alpha)$, Son- 


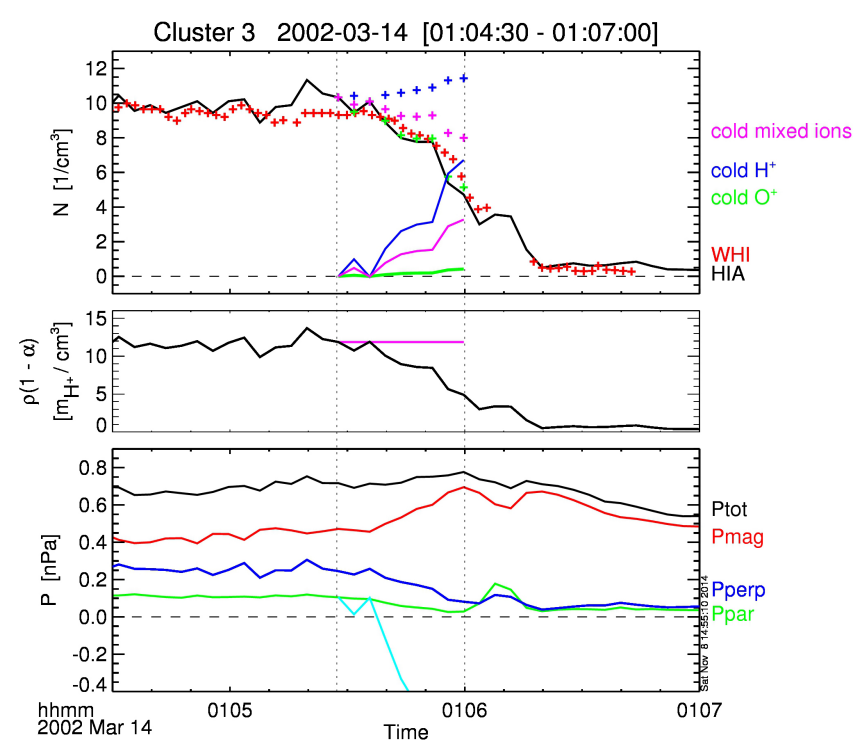

Figure 10. For the 14 March 2002 crossing, the figure shows, in the top panel, the evolution of ion (black trace) and total electron densities (red plus symbols) provided by HIA and WHISPER, respectively. The inferred densities of cold ions, either $\mathrm{H}^{+}$ (blue line) or $\mathrm{O}^{+}$(green line), or of a cold plasma mixture rich in heavy ions (magenta line) required to make $\rho(1-\alpha)$ constant during the Walén interval (vertical dotted lines) are also shown; the blue, green, and magenta plus symbols give the total electron number density, including the contribution required by the hypothetical cold $\mathrm{H}^{+}$or $\mathrm{O}^{+}$ions or by the cold plasma mixture, respectively. The middle panel shows the evolution of $\rho(1-\alpha)$. The bottom panel shows the magnetic field pressure, $p_{\text {mag }}$ (red), the perpendicular, $p_{\perp}$ (blue), and parallel, $p_{\|}$(green), plasma pressures, the total pressure $p_{\text {tot }}=p_{\text {mag }}+p_{\perp}$ (black), as well as the hypothetical $p_{\|}$(cyan trace) needed to make $\rho(1-\alpha)$ constant (only values above $-0.4 \mathrm{nPa}$ are shown).

nerup et al. (1995) have suggested that a narrow layer of heavier ions could have been missed as a result of 2 min time resolution for the AMPTE-CEE instrument. In our case this argument could, however, not apply to the entire reconnection exhaust region because, with a time resolution of $8 \mathrm{~s}$ of the CODIF composition measurements, that region is reasonably well resolved. Furthermore, with a $2 \mathrm{~s}$ time resolution, the WHISPER total number density measurements put a severe constraint on the presence of any hidden population.

The underlying assumptions of the ideal RD model, such as planarity and boundary thicknesses that are much larger than the relevant kinetic lengths, have been checked as well. For all cases presented in Sect. 4, various independent methods to estimate the magnetopause orientation and motion provided results consistent with a locally planar discontinuity, whose thickness is typically one order of magnitude bigger than the proton gyro radius and inertial length. The only exception is the ion gyro radius on 5 July 2001 event, which is only 5 times smaller than the magnetopause thickness.

\subsection{The potential role of hidden ion populations}

Given the limited energy range of the ion detectors, it cannot a priori be ruled out that ion populations hidden to the CIS instrument could possibly recover the $\rho(1-\alpha)=$ const. condition.

We first consider the hypothetical presence of ions with energies below the low-energy limit of the CIS instrument, i.e., $\sim 5 \mathrm{eV}$ for HIA and $\sim 25 \mathrm{eV}$ for CODIF. For the 14 March 2002 transition presented in Sect. 4.1, the top panel in Fig. 10 shows, as blue and green lines, the number density of cold ions, either $\mathrm{H}^{+}$or $\mathrm{O}^{+}$, respectively, that would be required to make $\rho(1-\alpha)$ constant at the level shown by the magenta horizontal line in the second panel. As the figure shows, the required density of hidden $\mathrm{H}^{+}$ions gives a total number density (blue plus symbols) totally inconsistent with the total electron density measured by WHISPER (red symbols). On the other hand, the required cold $\mathrm{O}^{+}$ions, $\approx 0.4 \mathrm{~cm}^{-3}$ at the end of the interval, would lead to a total density still consistent with the total electron density.

It is well known that cold ions from the plasmaspheric drainage plume can flow into the magnetopause, with densities often in excess of $10 \mathrm{~cm}^{-3}$ (e.g., Borovsky et al., 2013, and references therein). But because the plume consists predominantly of $\mathrm{H}^{+}$, the presence of such ions would lead to total number densities well in excess of the limit posed by WHISPER. Only a population consisting of just the right amount of $\mathrm{O}^{+}$, but no $\mathrm{H}^{+}$, would be a problem, but there is no evidence that this ever occurs. In the most unfavorable situation cited in Borovsky et al. (2013), i.e., a plasmasphere composition mix rich in heavy ions, having a relative abundance of $0.77,0.2$ and 0.03 for $\mathrm{H}^{+}, \mathrm{He}^{+}$and $\mathrm{O}^{+}$, respectively, the effective mass of the ions will be $2.05 \mathrm{amu}$. This corresponds to the magenta line in the top panel of Fig. 10, implying a total electron density shown with magenta symbols, well away from the WHISPER density (e.g., more that $50 \%$ at the end of the Walén interval). Furthermore, unless a certain mechanism exists that causes accumulation of cold plasma right at the magnetopause, the presence of plasmaspheric plasma inside the magnetosphere should have a signature in the WHISPER data. According to Borovsky et al. (2013), based on arguments of plasma conservation in magnetic flux tubes, one expects a slow increase in plasmaspheric density earthward of the magnetopause. That is contradicted by the sharp dropoff seen in the electron density measurements presented here. We thus can say with confidence that a hidden population of cold ions cannot be responsible for the failure of the $\rho(1-\alpha)=$ const. condition. The situation is the same for the other two cases: any hidden population consisting predominantly of $\mathrm{H}^{+}$ions will cause the total density to exceed the limit imposed by the measured WHISPER total electron densities.

Another possibility is to invoke a hidden population that changes $\alpha$. The cold ions just discussed would not matter here because their contribution to the ion pressure would be 
small or negligible. But magnetospheric energetic ions above the CIS energy range (i.e., above $40 \mathrm{keV}$ ) could have a strong influence on the plasma pressure while contributing little to its density. Pressure balance would, of course, put a constraint on this contribution. The last panel of Fig. 10, presents the evolution of the magnetic pressure, $p_{\text {mag }}$ (red), perpendicular, $p_{\perp}$ (blue), and parallel, $p_{\|}$(green), plasma pressures, as well as the total pressure, $p_{\text {tot }}=p_{\text {mag }}+p_{\perp}$ (black), during that event. The total pressure should be constant across the RD discontinuity, according to Eq. (4) from Sect. 1, and this is indeed approximately the case. In order not to destroy that balance, the hypothetical hidden energetic population would essentially only have to contribute to $p_{\|}$and much less to $p_{\perp}$, with apparent consequences for the pressure anisotropy $\alpha$. The cyan line in the last panel of Fig. 10 shows how $p_{\|}$should vary inside the RD in order to change $\alpha$ so that $\rho(1-\alpha)=$ const. (indicated by the magenta line in the second panel). But this would imply unphysical negative values for the parallel pressure. This hypothesis can therefore be ruled out. The same conclusion applies to the other two cases, too.

\subsection{Effect of $\mathrm{O}^{+}$ions on Walén test}

For the magnetopause transition analyzed in Sect. 4.3, a significant abundance of $\mathrm{O}^{+}$ions has been detected, yet $\rho(1-\alpha)$ is not conserved across the discontinuity, and the uni-fluid correction of the plasma moments proved to have basically no influence on its evolution. However, the $\mathrm{O}^{+}$presence in that event had an influence on the Walén test. As an average value of the results obtained when the analysis is performed on intervals of different length, the Walén slope increased by $\sim 10 \%$, from 0.67 to 0.74 , when, instead of the proton moments, the uni-fluid moments based on the onboard $\mathrm{O}^{+}$moments were used. The improvement was $\sim 6 \%$ on average, to 0.71 , when the uni-fluid moments based on the ground $\mathrm{O}^{+}$ moments were used. Although the uni-fluid correction brings the Walén slope closer to the ideal values of \pm 1 , it cannot explain entirely the long-standing issue of sub-Alfvénic plasma flow velocity during magnetopause reconnection events.

\subsection{Assuming $\rho(1-\alpha)=$ const. in the Walén relation}

In Sect. 1 reference was made to studies where the usual Walén relation was replaced by modified versions (Eqs. 5 or 6) that had the constancy of $\rho(1-\alpha)$ built into them. In those studies the resulting improvement in Walén slopes was attributed to the presence of unresolved minor ions. Our cases are no exception in this regard. For example, for the 14 March 2002 event presented in Sect. 4.1, the Walén slope improved very significantly, from -0.68 when using Eq. (2) to around -0.83 when using Eq. (6). Since we know that there were essentially no minor ions present, it follows that the improved slope must be a result of the $\alpha$ profile, as discussed below: it causes the mass density in the magne- topause and boundary layer to artificially increase, reducing the Alfvén speed and thus increasing the Walén slope.

Similarly, for the 5 July 2001 crossing presented in Sect. 4.2, the Walén slope improved from -0.85 when using Eq. (2) to around -0.97 when using Eq. (6).

Phan et al. (2004) employed Eq. (6) to analyze the magnetopause crossings from 26 January 2001. According to their Table 1, the average Walén slope for the 10 magnetopause transitions identified as RD was 0.89. Using the same intervals and satellite data, i.e., HIA on Cluster 1, the standard Walén relation (Eq. 2) gives slopes systematically lower, with an average value of 0.73 .

For the crossing analyzed in Sect. 4.3, using C4 proton data, the standard Walén relation (Eq. 2) provides a slope of 0.76 , whereas by employing Eq. (6) one obtains a slope of 0.94 . Although there is significant $\mathrm{O}^{+}$present in this event, it is nowhere near enough to cause such improved Walén slopes. In fact, as has been shown, when the unifluid correction is taken into account, the standard Walén relation provides a slope of around 0.83. Again, the justification for building the condition $\rho(1-\alpha)=$ const. directly into the Walén relation, based on assuming the presence of unresolved heavier ions, must be called into question.

The problem can be looked at from a more fundamental viewpoint: magnetopause observations show that, in general, $p_{\|}<p_{\perp}$ in the magnetosheath; see, e.g., the superposed epoch analysis and the individual events presented in Phan and Paschmann (1996) and Bauer (1997). This means that $\alpha \equiv\left(p_{\|}-p_{\perp}\right) \mu_{0} / B^{2}<0$, resulting in $(1-\alpha)>1$. Furthermore, the ion pressure within the magnetopause and boundary layer typically becomes more isotropic, i.e., $(1-\alpha)$ becomes close to unity. Figure 10 is an example of this exact behavior. Given such an $\alpha$ profile, the mass density would have to increase across the magnetopause to preserve $\rho(1-\alpha)$. In the past studies already referred to, increasing the effective mass of the ions looked like the solution, but as we have seen for the cases presented, there are not enough heavier ions to make this an option.

On the other hand, if there are no minor ions present at all, and $\alpha$ has its typical profile, then it is the number density that would have to increase in the magnetopause and boundary layer to keep $\rho(1-\alpha)$ constant, but such an increase is hardly ever observed. If the number density actually drops, as is the rule, then $\alpha$ would have to become more negative than in the magnetosheath, while in reality $\alpha$ is close to 0 or even positive.

\subsection{Conclusion}

For an ideal RD, $\rho(1-\alpha)$ should be constant. The fact that this is not true for the cases we have presented in this paper must mean that they do not represent ideal RDs, even though the Walén relation, the classical RD criterion, was reasonably well met. What causes this discrepancy is presently not understood. Further analysis would have to take into account 
effects due to the magnetopause deviation from the ideal RD model. These include possible nonuniform conditions in the magnetosheath and the fact that the Walén analysis relies on measurements taken on plasma that crossed the magnetopause at different locations. Also, since the particles may travel a long path along the magnetopause to the point of detection, time-of-flight and curvature effects on a bigger scale than the vicinity of the spacecraft could become important.

Acknowledgements. This work was supported by a grant of the Romanian ministry of Education, CNCS-UEFISCDI, project number PN-II-RU-PD-2012-3-0508. The authors thank the Cluster FGM, CIS and WHISPER instrument teams for the data used in this study. We thank Iannis Dandouras and Alain Barthe from Institut de Recherche en Astrophysique et Planétologie in Toulouse (former CESR) for supplying the CODIF oxygen onboard moments for the highest energy range and Irina Galkina and Antoine Denazelle from Laboratoire de Physique et Chimie de l'Environnement et de l'Espace in Orléans for supplying the WHISPER electron densities for the 26 January 2001 event. We thank the ACE SWEPAM instrument team and the ACE Science Center for providing the ACE data. G. Paschmann wishes to acknowledge support from the International Space Science Institute in Bern in the framework of an International Team.

Topical Editor C. Owen thanks J. De Keyser and one anonymous referee for their help in evaluating this paper.

\section{References}

Balogh, A., Carr, C. M., Acuña, M. H., Dunlop, M. W., Beek, T. J., Brown, P., Fornacon, K.-H., Georgescu, E., Glassmeier, K.H., Harris, J., Musmann, G., Oddy, T., and Schwingenschuh, K.: The Cluster Magnetic Field Investigation: overview of in-flight performance and initial results, Ann. Geophys., 19, 1207-1217, doi:10.5194/angeo-19-1207-2001, 2001.

Bauer, T. M.: Particles and Fields at the Dayside Low-latitude Magnetopause, Ph.D. thesis, Max-Planck-Institut für extraterrestrische Physik, Garching, Germany, 1997.

Blagau, A.: Characteristics of Earth's magnetopause from Cluster measurements, Ph.D. thesis, Max-Planck-Institut für extraterrestrische Physik, Garching, Germany, available at: http://edoc. ub.uni-muenchen.de/7806/ (last access: 12 January 2015), 2007.

Borovsky, J. E., Denton, M. H., Denton, R. E., Jordanova, V. K., and Krall, J.: Estimating the effects of ionospheric plasma on solar wind/magnetosphere coupling via mass loading of dayside reconnection: Ion-plasma-sheet oxygen, plasmaspheric drainage plumes, and the plasma cloak, J. Geophys. Res., 118, 5695-5719, doi:10.1002/jgra.50527, 2013.

Décréau, P. M. E., Fergeau, P., Krasnoselskikh, V., Le Guirriec, E., Lévêque, M., Martin, Ph., Randriamboarison, O., Rauch, J. L., Sené, F. X., Séran, H. C., Trotignon, J. G., Canu, P., Cornilleau, N., de Féraudy, H., Alleyne, H., Yearby, K., Mögensen, P. B., Gustafsson, G., André, M., Gurnett, D. C., Darrouzet, F., Lemaire, J., Harvey, C. C., Travnicek, P., and Whisper experimenters: Early results from the Whisper instrument on Cluster: an overview, Ann. Geophys., 19, 1241-1258, doi:10.5194/angeo-19-1241-2001, 2001.
Fuselier, S. A., Shelley, E. G., and Klumpar, D. M.: Mass density and pressure changes across the dayside magnetopause, J. Geophys. Res., 98, 3935-3942, doi:10.1029/92JA02236, 1993.

Haaland, S. E., Sonnerup, B. U. Ö., Dunlop, M. W., Balogh, A., Georgescu, E., Hasegawa, H., Klecker, B., Paschmann, G., Puhl-Quinn, P., Rème, H., Vaith, H., and Vaivads, A.: Fourspacecraft determination of magnetopause orientation, motion and thickness: comparison with results from single-spacecraft methods, Ann. Geophys., 22, 1347-1365, doi:10.5194/angeo-221347-2004, 2004.

Hudson, P. D.: Discontinuities in an anisotropic plasma and their identification in the solar wind, Planet. Space Sci., 18, 1611$1622,1970$.

Khrabrov, A. V. and Sonnerup, B. U. Ö.: deHoffmann-Teller Analysis, in: Analysis Methods for Multi-Spacecraft Data, edited by: Paschmann, G. and Daly, P. W., ISSI SR-001, 221-248, ESA Publications Division, 1998a.

Khrabrov, A. V. and Sonnerup, B. U. Ö.: Orientation and motion of current layers: Minimization of the Faraday residue, Geophys. Res. Lett., 25, 2373, doi:10.1029/98GL51784, 1998 b.

Mouikis, C. G., Kistler, L. M., Wang, G., and Liu, Y.: Background subtraction for the Cluster/CODIF plasma ion mass spectrometer, Geosci. Instrum. Method. Data Syst., 3, 41-48, doi:10.5194/gi-3-41-2014, 2014.

Paschmann, G., Baumjohann, W., Sckopke, N., Papamastorakis, I., and Carlson, C. W.: The magnetopause for large magnetic shear AMPTE/IRM observations, J. Geophys. Res., 91, 11099-11115, doi:10.1029/JA091iA10p11099, 1986.

Paschmann, G., Fuselier, S. A., and Klumpar, D. M.: High-speed flows of $\mathrm{H}(+)$ and $\mathrm{He}(2+)$ ions at the magnetosphere, Geophys. Res. Lett., 16, 567-570, doi:10.1029/GL016i006p00567, 1989.

Paschmann, G., Haaland, S., Sonnerup, B. U. Ö., Hasegawa, H., Georgescu, E., Klecker, B., Phan, T. D., Rème, H., and Vaivads, A.: Characteristics of the near-tail dawn magnetopause and boundary layer, Ann. Geophys., 23, 1481-1497, doi:10.5194/angeo-23-1481-2005, 2005.

Paschmann, G., Øieroset, M., and Phan, T.: In-Situ Observations of Reconnection in Space, Space Sci. Rev., 178, 385-417, doi:10.1007/s11214-012-9957-2, 2013.

Phan, T. D. and Paschmann, G.: Low-latitude dayside magnetopause and boundary layer for high magnetic shear 1 . Structure and motion, J. Geophys. Res., 101, 7801-7816, doi:10.1029/95JA03752, 1996.

Phan, T.-D., Paschmann, G., and Sonnerup, B. U. Ö.: Low-latitude dayside magnetopause and boundary layer for high magnetic shear 2. Occurrence of magnetic reconnection, J. Geophys. Res., 101, 7817-7828, doi:10.1029/95JA03751, 1996.

Phan, T. D., Dunlop, M. W., Paschmann, G., Klecker, B., Bosqued, J. M., Rème, H., Balogh, A., Twitty, C., Mozer, F. S., Carlson, C. W., Mouikis, C., and Kistler, L. M.: Cluster observations of continuous reconnection at the magnetopause under steady interplanetary magnetic field conditions, Ann. Geophys., 22, 23552367, doi:10.5194/angeo-22-2355-2004, 2004.

Rème, H., Aoustin, C., Bosqued, J. M., Dandouras, I., Lavraud, B., Sauvaud, J. A., Barthe, A., Bouyssou, J., Camus, Th., Coeur-Joly, O., Cros, A., Cuvilo, J., Ducay, F., Garbarowitz, Y., Medale, J. L., Penou, E., Perrier, H., Romefort, D., Rouzaud, J., Vallat, C., Alcaydé, D., Jacquey, C., Mazelle, C., d’Uston, C., Möbius, E., Kistler, L. M., Crocker, K., Granoff, M., Mouikis, C., Popecki, 
M., Vosbury, M., Klecker, B., Hovestadt, D., Kucharek, H., Kuenneth, E., Paschmann, G., Scholer, M., Sckopke, N., Seidenschwang, E., Carlson, C. W., Curtis, D. W., Ingraham, C., Lin, R. P., McFadden, J. P., Parks, G. K., Phan, T., Formisano, V., Amata, E., Bavassano-Cattaneo, M. B., Baldetti, P., Bruno, R., Chionchio, G., Di Lellis, A., Marcucci, M. F., Pallocchia, G., Korth, A., Daly, P. W., Graeve, B., Rosenbauer, H., Vasyliunas, V., McCarthy, M., Wilber, M., Eliasson, L., Lundin, R., Olsen, S., Shelley, E. G., Fuselier, S., Ghielmetti, A. G., Lennartsson, W., Escoubet, C. P., Balsiger, H., Friedel, R., Cao, J.-B., Kovrazhkin, R. A., Papamastorakis, I., Pellat, R., Scudder, J., and Sonnerup, B.: First multispacecraft ion measurements in and near the Earth's magnetosphere with the identical Cluster ion spectrometry (CIS) experiment, Ann. Geophys., 19, 1303-1354, doi:10.5194/angeo19-1303-2001, 2001.
Sonnerup, B. U. Ö. and Scheible, M.: Minimum and maximum variance analysis, in: Analysis Methods for Multi-Spacecraft Data, edited by: Paschmann, G. and Daly, P. W., ISSI Scientific Reports, p. 185, ESA Publications Division, 1998.

Sonnerup, B. U. Ö., Papamastorakis, I., Paschmann, G., and Luehr, H.: Magnetopause properties from AMPTE/IRM observations of the convection electric field - Method development, J. Geophys. Res., 92, 12137-12159, doi:10.1029/JA092iA11p12137, 1987.

Sonnerup, B. U. Ö., Paschmann, G., and Phan, T.-D.: Fluid Aspects of Reconnection at the Magnetopause: In Situ Observations, Physics of the Magnetopause, 167-180, 1995. 